\title{
O Panorama das Drogas no México: da margem da sociedade ao centro da cultura'
}

DIANA PALAUERGICH:

\section{Resumo}

O artigo destaca o percurso das manifestações culturais ligadas ao tráfico de drogas no México, de um lugar marginal, de subcultura, na sociedade mexicana das décadas de 1970 e 1980, expressas principalmente através dos narcocorridos e do narcocine, para um lugar no mainstream cultural mexicano, desde o início do século 21, com destaque especial para a narcoliteratura. O aumento da violência, provocado pela guerra ao narcotráfico, produz uma proliferação da temática nos meios de comunicação e se reflete em áreas da cultura como as artes plásticas e a literatura, produzindo um novo tipo de expressão artística ou narrativa, que tanto pode ser oportunista e contribuir para a banalização da violência do narcotráfico como ser crítica e narrar o impacto individual e coletivo do tráfico de drogas, narrar a desenfreada e violenta realidade mexicana sem cair no estilo da imprensa marrom, do folclore ou dos lugares comuns dos romances de ação.

Palavras-chave: Literatura e Violência. Narcoliteratura. Cultura Mexicana. México.

\footnotetext{
${ }^{1}$ Tradução para o português: Alessandra Bourdot.

* Universidade de Nova Gales do Sul, Sidney, Austrália.
} 


\title{
The drugs scenario in Mexico: from the outskirts of society to mainstream culture
}

\begin{abstract}
This article points out the trajectory of cultural expressions linked to drug trafficking in Mexico, from a marginal position, as a subculture, in the Mexican society of the 1970s and 1980s - mainly in the form of narcocorridos and narcocine - to a place within Mexican mainstream culture, as of the beginning of the $21^{\text {st }}$ century, with particular emphasis on narcoliterature. The escalation of violence, precipitated by the war on drugs, leads to the propagation of the issue in the media with effects on many cultural fields such as the plastic arts and literature, thus producing a new kind of artistic expression or narrative that may either appear as opportunistic and contribute to the banalization of drug trafficking violence or be critical and recount the individual and collective effects of drug trafficking, narrate the rampant and violent Mexican reality without falling into the yellow press style, folklore or action novel clichés.
\end{abstract}

Keywords: Literature and Violence. Narco-literature. Mexican culture. Mexico.

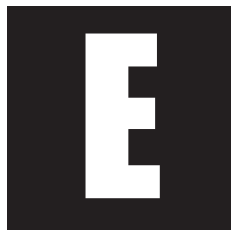

nquanto nos anos 1970 era possível argumentar que os traficantes de drogas constituíam uma subcultura minoritária que existia à margem da sociedade mexicana limitada à região norte, tradicionalmente envolvida na produção e tráfico de entorpecentes - este não tem sido o caso na última década, quando a visibilidade do poder financeiro, político e de fogo dos traficantes por todo país aponta para o fato de que eles representam uma força excepcional que, ao longo do tempo, conseguiu passar da margem da sociedade para o centro.

Enquanto nos anos 1970 e 1980 as manifestações culturais mais divulgadas e comercializadas desse fenômeno eram os narcocorridos e o 
narcocine - consumidos principalmente à margem da cultura dominante na região norte e entre os imigrantes mexicanos do outro lado da fronteira - desde o início desse século esses temas se deslocaram para o centro do mainstream cultural mexicano, chegando a se estabelecer de maneira destacada nos meios de comunicação, nas artes visuais e na literatura.

\section{$1 \mathrm{O}$ jornalismo diante do fenômeno das drogas}

Deve-se observar que o fator mais óbvio a contribuir para a proliferação de obras que tratam do fenômeno das drogas, tanto no jornalismo como no campo das letras e artes visuais, é o aumento da violência, desde que o presidente Felipe Calderón iniciou a luta contra o narcotráfico, em 2006, poucos meses depois de assumir o comando do país. À medida que cresce a representação desse tema em diversos meios do mainstream cultural, aumentam também as críticas à atual comercialização e representação do tema. Alega-se que o interesse exagerado pelo fenômeno das drogas e de sua comercialização legitima esse negócio ilegal, promove a violência e contribui para uma imagem ruim do país no exterior.

Quanto aos comentários sobre a cobertura da mídia, o renomado historiador mexicano Enrique Krauze, em seu artigo Em defesa da nossa imagem, publicado na revista Proceso em 2009, critica a mídia impressa do país por sua cobertura sensacionalista do tema, especialmente a ênfase nas imagens sangrentas, a qual, de acordo com o autor, fornece publicidade gratuita para os cartéis. Embora não haja dúvidas de que não faltam meios de comunicação e jornalistas no país abordando o tema de maneira sensacionalista e pouco analítica, como advertiu Krauze, alimentando o interesse mórbido do público ante as imagens de corpos decapitados e desmembrados, seria errado concluir que este é o caso do jornalismo mexicano como um todo. Em primeiro lugar, devemos reconhecer a exis- 
tência de diferenças consideráveis entre a relativa liberdade desfrutada pelos meios de comunicação na capital e a intensa (auto)censura aplicada aos meios de comunicação ao norte do país, devida ao clima de intimidação e inquietação gerado pelas ameaças e execuções de jornalistas por parte dos traficantes. Esse silenciamento é, certamente, mais evidente nas zonas controladas pelos Zetas e pelo Cartel do Golfo, como Tamaulipas, por exemplo, onde, segundo investigação da Fundação Mexicana de Jornalismo realizada em 2010, são relatados apenas 0-5\% dos crimes relacionados com o tráfico de drogas.

Em segundo lugar, é necessário observar que, além da cobertura sensacionalista da narcoviolência, no México também ocorre o que o jornalista de Monterrey, Diego Enrique Osorno, chamou de "jornalismo infrarrealista" para se referir à prática de um jornalismo comprometido, urgente e de trincheira, dedicado à tarefa de revelar pontos fracos das grandes notícias da mídia; de contar histórias não contadas de homens e mulheres comuns, cuja experiência de vida e de morte não interessa ao discurso oficial:

O jornalismo infrarrealista sabe que a retórica de guerra é diferente da guerra. O jornalismo infrarrealista não conta mortos, conta as histórias dos mortos. O jornalismo infrarrealista busca a versão daqueles que não têm porta-voz nem departamento de comunicação, de quem nunca convocou uma coletiva de imprensa.

Na verdade, esse termo poderia também definir o trabalho de todo um grupo de jornalistas mexicanos, entre os quais se destacam, por sua audácia, as mulheres. Só durante o ano de 2011, cinco delas abordaram temas atuais e de alto risco: Lydia Cacho, o tráfico e abuso de meninas e mulheres; Ana Lilia Pérez, as ligações sombrias entre o chamado crime organizado e a empresa mais importante do México, Petróleos Mexicanos (Pemex); Anabel Hernández, a estreita relação entre diferentes instituições do governo mexicano, o mundo empresarial e o tráfico de drogas; 
enquanto Marcelas Turatti e Sanjuana Martínez mostram a experiência das pessoas atingidas pela violência das drogas e dão voz à dor dos familiares dos mortos. É importante dizer que todas tiveram suas vidas ameaçadas, o que já levou, até o momento, duas delas para o exílio: Lydia Cacho e Ana Lilia Pérez. ${ }^{2}$

\section{As artes plásticas diante do fenômeno das drogas}

Das primeiras páginas de jornais e noticiários, o tema das drogas se transferiu para as telas e ateliês dos artistas mexicanos. Para mencionar apenas alguns de seus expoentes principais com maior ressonância nacional e internacional: Teresa Margolles, Lenin Márquez e Rodrigo Delgado Herbert, criadores de obras controversas que despertaram o interesse da mídia internacional, mas que também provocaram no país o repúdio de alguns setores da crítica e do público em geral, que não veem nessas obras um questionamento e estudo crítico do fenômeno que marcou profundamente a sociedade mexicana, mas apenas a apologia ao tráfico de drogas e a exploração oportunista de um tema em evidência. ${ }^{3}$

\footnotetext{
${ }^{2}$ Nesse contexto de jornalismo contestador ou infrarrealista, como diria Osorno, é importante mencionar também o trabalho de outra mulher: Lolita Bosch. Em 2010, após a descoberta de 72 imigrantes assassinados no rancho de San Fernando, ela passou a gerenciar o site Nuestra aparente rendición, cuja intenção, semelhante a dos Periodistas de a Pie, como assinala a autora, é "gerar reflexão, consciência, crítica, debate [...] reunir vozes para pensar em conjunto sobre o que está ocorrendo no México, algo imenso e impossível de entender sem a ajuda de outras pessoas [...]". Veja: http://www.nuestraaparenterendicion.com

${ }^{3}$ Nesse contexto vê-se, por exemplo, a resenha da exposição de Teresa Margolles na Bienal de Veneza em 2009, na qual, referindo-se à representação da narcoviolência pela artista de Sinaloa, a crítica Avelina Lésper afirma: Esta farsa representa o México e diz ao mundo que nosso problema mais grave, o narcotráfico, é visto como uma farsa sensacionalista para a arte e para as autoridades de cultura. Essa é a nossa visão de mais de 13 mil mortes: um cenário e uma ideia com nível de filmes $B$ de terror ( $\mathrm{O}$ artigo original pode ser encontrado no Blog de Lésper: http://www.avelinalesper.com/2009/09/farsa-en-venecia.html)
} 
No campo das artes plásticas, Lenin Márquez intervém de forma radical e irônica no gênero paisagem e pintura 'em série', de maneira realista, versões literais de uma natureza morta peculiar ao estilo de Sinaloa: cadáveres de pessoas executadas semeados como plantas nos campos e estradas de seu estado. Representados a uma distância objetivo-emotiva que por sua vez reflete a insensibilidade contemporânea diante do espetáculo diário da morte violenta, seus quadros mostram homens jovens deitados no chão em posições diferentes, rodeados por símbolos de sua profissão - ofertas contemporâneas - pistolas e rifles, balas espalhadas, latas de bebidas.

Uma proposta plástica interessante do tema é a do artista de Tamaulipas, Ricardo Delgado Herbert, que há mais de uma década explora a iconografia da fronteira, cujos elementos inevitáveis são também os traficantes de drogas. Em séries como Arte Huerco: Ranger Time, Glorius Pistols: de A a Z, e Riscos patrióticos - esta última censurada em seu estado, por supostamente legitimar a narcoviolência - o pintor oferece uma visão caricatural e grotesca dos traficantes, marcada visualmente pelo kitch como núcleo da "narcoestética".

Em termos de reconhecimento internacional e presença nos circuitos de arte global, destaca-se o trabalho da artista conceitual Teresa Margolles, de Sinaloa, que passou três décadas explorando a morte, o sepultamento e os restos mortais. Nos últimos anos, com o aumento da violência das drogas, a exploração da morte ganhou uma dimensão adicional. Sua instalação "21 acertos de contas", por exemplo, consiste em uma mostra de 21 jóias criadas ao estilo barroco preferido pelos traficantes, no qual incorpora found objects, pedaços de vidro ou balas coletadas de lugares onde foram achados os corpos dos traficantes executados.

Em sua exposição intitulada De que mais poderíamos falar?, com a qual representou seu país na Bienal de Veneza, em 2009, a artista escolheu cobertores manchados de sangue dos mortos pela narcoviolência como um 
emblema do México contemporâneo, e distribui aos visitantes cartões plastificados, intitulados Cartão para separar cocaína, que mostram a imagem em close do rosto machucado de um dos mortos. O rosto inchado de um cadáver, o espetáculo do sangue e o clima sombrio do espaço da exposição perturbam a sensibilidade dos visitantes, obrigando-os a reconhecer a existência de uma relação intrínseca entre o prazer dos consumidores de drogas ilícitas - localizados principalmente nos países desenvolvidos, em especial nos Estados Unidos - e a violência que abala o México.

\section{Narcoliteratura: as letras mexicanas diante do fenômeno das drogas}

Críticas semelhantes às dirigidas contra os artistas visuais sobre a exploração comercial e, portanto, pouco ética do tema, são frequentes também no campo da literatura, sendo essa a corrente cultural na qual se registra a maior proliferação de obras que abordam o fenômeno das drogas. O excesso de títulos surgidos recentemente, tanto no campo do jornalismo investigativo como na ficção, cria a impressão de que o mundo editorial mexicano vive, há pelo menos uma década, um tipo de "linha de produção narco" (narcomaquila) literária que com rapidez assustadora despeja grandes quantidades do mesmo produto (ou, pelo menos, muito semelhantes).

Com relação à ficção que tem as drogas como tema, sobre a qual se concentra este ensaio, é importante destacar a mudança ocorrida na publicação e divulgação nos últimos dez anos. Publicada antigamente por pequenas editoras da região norte e praticamente sem nenhuma distribuição no resto do país, a "narconarrativa" começou a ser difundida no começo desse novo século por grandes multinacionais com filiais no México, tais como Random House Mondadori, Planeta, Alfaguara (Santillana), Grijalbo ou Tusquets, que já haviam "embalado" com muito su- 
cesso, tanto para venda local como internacional, a narrativa colombiana que aborda tema similar. ${ }^{4} \mathrm{O}$ interesse dos grupos editoriais pela temática narco indica o valor mercadológico desta narrativa e constitui um fator decisivo na padronização e popularização desse fenômeno.

No entanto, é necessário esclarecer, com relação ao campo da ficção, que este boom editorial não se traduziu - como se poderia supor - em narconovelas best-sellers, mas especialmente em um crescente número de autores que abordam esse tema, como também na abundância de títulos publicados todos os anos por essas editoras. Elas não apenas contribuíram para a legitimação da narconovela mexicana, como também desempenharam um papel importante na transformação de uma modalidade literária regional em uma modalidade literária sem território definido, produzida não apenas ao norte como também por todo país e no exterior, onde a questão das drogas vem sendo abordada tanto por autores consagrados como por emergentes. ${ }^{5}$ Ao norte, a temática narco foi abordada, entre outros, por Orfa Alarcón, Leónidas Alfaro, Julian Herbert, Élmer Mendoza, Eduardo Antonio Parra, Hilario Peña, Victor Hugo Rascón Banda, Juan José Rodriguez, Albaro Sandoval, Miguel Tapia, Carlos Velázquez, e Heriberto Yépez. Em outras partes do país, esse tema foi tratado por Homero Aridjis, Bernardo Bef Fernández, Carlos Fuentes, Iris García, Sergio González Rodríguez, Mario González Suárez, Yuri Herrera, Rafael Ramírez Heredia, Martín Solares, Juan Pablo Villalobos, Juan Villoro, entre outros.

\footnotetext{
${ }^{4}$ Eu uso o termo narconarrativa ou narconovela para descrever uma linha crescente de textos de diversos estilos, temáticas e qualidades literárias que exploram, direta ou indiretamente, a presença dos traficantes e o tráfico de drogas na sociedade mexicana. De modo algum atribuo uma carga negativa, como visto frequentemente nas resenhas desta narrativa nos meios de comunicação mexicanos, onde muitas vezes o gênero é sinônimo de literatura inferior. O uso pejorativo do conceito levou vários autores de romances que, sem dúvida, exploram a cultura narco (Yuri Herrera, Alejandro Paez, Hilario Peña) a rejeitar a definição de que escrevem narconovelas.

${ }^{5}$ Depois de acolhida e promovida pelos sistemas mercadológicos das grandes editoras multinacionais, a narconarrativa perde sua antiga força contestatória e anti-hegemônica para se tornar o exemplo mais recente da 'exótica barbárie' mexicana.
} 
Não é de surpreender que, diante da avalanche de publicações e da agressiva ação de marketing da narconarrativa, o establishment cultural mexicano seja cético com relação ao valor literário da mesma. Os críticos, tais como Rafael Lemus, Cristopher Michael Domínguez, Héctor de Malueón, Sergio Rodríguez González e Orlando Ortiz, os quais analisam a narconarrativa, em páginas de revistas e jornais de grande circulação, compartilham da mesma posição sobre a comercialização dessa literatura. Todos, sem exceção, lamentam a ausência do grande romance sobre o tráfico de drogas e criticam a proliferação daquilo que o renomado crítico mexicano Cristopher Michael Domínguez descreveu como novelinhas dispensáveis que perderão toda a relevância quando se falar em México nos tempos das guerras das drogas. A essas críticas deve ser adicionada, também, a opinião da escritora e jornalista catalã-mexicana Lolita Bosch que, nas páginas do diário espanhol El País, identificou uma característica particular dessa narrativa, não percebida pelos resenhistas mencionados: a ausência de uma postura ética do autor diante do assunto que narra.

\section{Dois casos notáveis de narconarrativa mexicana}

No que será apresentado a seguir, meu objetivo é extrair do vasto conjunto da narconarrativa mexicana - de fato, de qualidade literária muito variada - duas obras excepcionais: a primeira, Contrabando (2008), do dramaturgo de Chihuahua, Víctor Hugo Rascón Banda - que considero uma obra-prima do narcotráfico mexicano - e a segunda, um curto mas poderoso texto do jovem jornalista de Monterrey, Diego Enrique Osorno, Un vaquero cruza la frontera en silencio (2011), o qual, embora não se destaque por uma excepcional qualidade literária como o romance Contrabando - de qualquer modo, literaturnost/literariedade não é seu objetivo principal -, compartilha com o trabalho de Rascón Banda 
de uma profunda postura ética para com o assunto narrado, ausente no grupo da narconarrativa mexicana, dominada pelo romances policiais, de suspense e algumas narcofábulas e narcoparódias. Por postura ética, refiro-me, certamente, à responsabilidade pessoal e ao compromisso moral que assume um autor frente ao momento histórico que vive e o tema que narra, e cujo resultado é uma obra com profundo impacto sobre o leitor e que contribui para a compreensão da situação existencial e do sofrimento do outro.

Escrita em 1991 e ganhadora do prêmio Juan Rulfo no mesmo ano, o romance Contrabando permaneceu inédito até sua publicação pela Planeta, em 2008, após a morte prematura de seu autor, surgindo, assim, em pleno auge da narcoviolência, cujas dimensões épicas o escritor havia registrado e anunciado profeticamente duas décadas antes. Pela distância histórica de uns vinte anos, o romance pode ser lido como um tipo de memória assustadora do futuro, uma obra visionária que apresenta o narcotráfico como uma tragédia grega de proporções épicas, onde as causas sociais, culturais e históricas da violência se misturam ao destino trágico e universal do ser humano. A obra não é apenas brilhante em sua visão do narcotráfico como a grande tragédia mexicana, mas também na sua concepção literária, em que o autor criou um gênero híbrido, romanceroteiro-poesia-peça de teatro-testemunho, que permitiu captar de diferentes ângulos da narração as muitas facetas deste infortúnio nacional.

A obra foi construída como um texto polifônico. A cada capítulo - como um túmulo solitário de Comala - uma alma perdida conta sua história e pede, em vão, justiça ou vingança. Este é o caso de Damiana Carraveo, "uma mulher morta em vida" que aparece em uma estrada de terra na escuridão da noite diante do carro em viajam Víctor Hugo e seu pai. Damiana pede que alguém conte sua história devastadora: a perda de toda sua família no massacre da aldeia de Yepachi, sendo depois ela 
mesma torturada, presa e injustamente acusada de ser a líder de uma gangue de traficantes. Há também o testemunho de Jacinta Primera, antiga rainha das Festas do Terceiro Centenário que, encantada em sua juventude pelo brilho e ousadia de um jovem traficante, perde a graça e a beleza e vê seu amante desaparecer. Sua decadência física, sobre a qual discorre em todo seu testemunho, reflete em um nível metafórico a destruição de todo um povo pelos efeitos do narcotráfico.

Rascón Banda devolve a humanidade, o nome próprio e os traços pessoais a cada personagem. A micro-história de cada um, reconstruída em uma série de testemunhos feitos magistralmente, reflete a macro-história silenciada dos povos do norte, historicamente mais envolvidos e afetados pelo tráfico de drogas. O autor coloca o leitor na primeira fila do drama humano, como testemunha da solidão e do abandono de um povo deixado à mercê do tráfico e de policiais; de comunidades que parecem estar por trás de um país que durante tempo demais ignorou a realidade do narcotráfico, desprezada como um fenômeno exclusivo do norte do país.

Rascón Banda constrói o romance com traços de realidade viva e elementos autobiográficos, aparecendo como protagonista no papel de um jornalista e escritor. Na qualidade de advogado que mora na capital, seus parceiros, camponeses e outros personagens de sua cidade natal, Santa Rosa de Uruáchic, desprovidos de poder e proteção, esperam que denuncie e difunda publicamente as injustiças e abusos que sofrem por parte da polícia e dos traficantes que, como afirmam vários personagens do livro, são a mesma pessoa. O autor não apenas relata testemunhos ouvidos, como também questiona de forma autorreferencial assuntos chave relacionados com a representação literária do tema das drogas: o primeiro, a posição ética do escritor frente ao tema que apresenta - a postura que, como foi dito anteriormente, falta à maioria das narconovelas - e, o segundo, a busca de um gênero literário idôneo para captar o sentido da tragédia individual e coletiva dos povos do norte flagelados pela violência. 
Vivenciada e sentida a partir de dentro, do conhecimento privilegiado de um escritor da zona de Chihuahua onde se passa o romance, a visão épica e profundamente ética de Rascón Banda sobre o narcotráfico, como um destino maldito dos povos do norte e uma inevitabilidade histórica, diverge radicalmente da abordagem de grande parte da narconarrativa mexicana surgida após o boom editorial, cujos autores tendem a abordar o tema a partir da representação nos meios de comunicação, no jornalismo sangrento, nos mitos perpetuados nos narcocorridos, ou no cinema hollywoodiano. Seus excepcionais valores éticos e estéticos, sua validade e sua habilidade de transcender o limite local e apontar para o universal, fazem de Contrabando o grande romance do narcotráfico, aquele cuja ausência os críticos mexicanos lamentam, e que até o momento não notaram o valor extraordinário desse romance.

Ao longo dos anos, essa obra não apenas resistiu ao teste do tempo - o melhor juiz de qualidades literárias - como também parece ser mais relevante hoje do que quando foi escrita há duas décadas. Por mais radical que minha proposta possa parecer, acredito que a narconovela mexicana atingiu o auge vinte e um anos antes de começar o boom editorial desta modalidade literária, ou seja, quando foi escrito em 1991, Contrabando, de Víctor Hugo Rascón Banda, até hoje insuperável tanto estética como eticamente.

A segunda obra que merece ser destacada por sua exemplar postura ética com o tema abordado é o texto de Diego Osorno, Un vaquero cruza la frontera en silencio, uma obra híbrida que mistura biografia, testemunhos, ficção, poesia, crônica, ensaio jornalístico e fotográfico. É interessante notar que este texto é distribuído de forma independente das forças de mercado, pois foi editado e é divulgado gratuitamente pelo Conapred (Conselho Nacional Para Prevenir a Discriminação). Nele, Osorno conta duas histórias paralelas de silêncio. A primeira trata da trajetória pessoal de seu tio Gerónimo González Garza, um homem surdo-mudo nascido em Rancho Nuevo, nos arredores de Los Ramones, a 150 quilômetros 
ao norte de Monterrey, a quem o sobrinho havia prometido há muitos anos escrever a história de sua vida: uma vida de discriminação e oportunidades limitadas no México, travessias ilegais aos Estados Unidos, e viagens na década de 70 atuando no lado gringo da fronteira na venda chaveiros junto com seus amigos, um grupo variado de jovens hippies e surdos-mudos mexicanos, com os quais descobre um mundo diferente de oportunidades e serviços especiais, e a possibilidade de uma vida social que, no México, nunca puderam desfrutar.

A vida de Gerónimo está definida desde sua infância por sua múltipla condição de marginalizado: é pobre, vive na zona rural, é deficiente, e mais à frente se torna um imigrante ilegal.

A segunda história de silêncio contada é a história da fronteira nordeste, em particular a chamada Frontera Chica - a estreita área fronteiriça de Tamaulipas entre Reynosa e Novo Laredo - que desde a explosão da narcoviolência na região, em fevereiro de 2010, tornou-se a parte mais perigosa do território mexicano. Como afirma o autor, trata-se de uma área cuja história de terror - de massacres em massa, cidades fantasmas e fazendas abandonadas por seus habitantes depois de eclodir esse fogo cruzado entre diversos grupos criminosos e entre estes e o próprio governo federal - ainda não tinha sido contada.

O conceito de silêncio e como dar voz aos silenciados, algo omitido nos grandes relatos oficiais e na mídia escrita por quem tem acesso ao poder e à palavra, é a preocupação central deste livro, o qual coloca explicitamente uma pergunta que marca todo o texto: Como escrever sobre o silêncio? (Osorno, 2011, p. 70). Esta pergunta refere-se tanto ao silêncio sensorial-auditivo em que vive seu tio como ao silêncio real e metafórico dessa fronteira indescritível onde a barbárie não tem nome (Osorno, 2011, p. 20). Trata-se de um silêncio tanto imposto como autoimposto, manifesto em vários níveis: em menor medida, no silenciamento promovido 
pelos governos estaduais e municipais para não prejudicar a imagem da região nordeste; e, em maior medida, na existência de fato de uma lei da mordaça: o rígido controle da informação que, nessa e em outras partes do país, é exercido pelos senhores do tráfico, punindo com torturas e mortes morbidamente coreografadas nas reportagens sobre a violência disseminadas nos meios de comunicação e redes sociais. Compreendida nesse contexto mais amplo da violência e do mutismo em que vive afundada a fronteira nordeste, a história pessoal de Gerónimo ganha um significado adicional e pode ser compreendida também como uma poderosa metáfora da fronteira nordeste como uma região sem voz, paralisada e amordaçada pelo medo e pela violência.

O texto também consiste de outras duas seções que complementam a história do tio: um ensaio fotográfico de título sugestivo, El vaquero que no escucha los caballos relinchar, de Rodrigo Vázquez, e um epílogo em que se ouve a voz coletiva de San Fernando, um município de Tamaulipas que entrou para a história em agosto de 2010, quando, em uma das fazendas vizinhas, foram descobertos os corpos de 72 imigrantes massacrados. As fotografias complementam a narração capturando a poesia do cotidiano de Gerónimo em suas tarefas diárias na fazenda, com sua mulher e sua família, suas idas e vindas aos Estados Unidos. As imagens refletem a domesticidade e tranquilidade da fazenda, cuja aparente normalidade e silêncio do mundo em que vivem submersos o tio e sua mulher, fornecem um contraste com a paisagem da narcoguerra e o ruído ensurdecedor de tiros e explosões que os rodeiam e que não podem ouvir.

O ensaio fotográfico marca também uma fronteira simbólica entre a primeira parte do livro, Un vaquero cruza la frontera en silencio, e o epílogo intitulado Habla San Fernando, no qual Osorno assume o papel de cronista de San Fernando que, após ter sido atingida pela "Guerra" - com maiúscula para realçar sua magnitude -, deixou de ser um lugar e um lar para se tornar 
uma "boca", isto é, um ponto estratégico disputado por dois grupos principais do crime organizado da região: os Zetas e o Cartel do Golfo. A segunda parte do epílogo é escrita como um poema em primeira pessoa, no qual fala a voz coletiva de San Fernando que se recusa a passar para a história como o local infernal transformado no túmulo de imigrantes assassinados, mártires e heróis desse poema de denúncia e testemunho.

Visto em seu conjunto, Un vaquero cruza la frontera en silencio, denuncia a dimensão multifatorial da discriminação no México, a crueldade e a insensibilidade de toda uma sociedade para com o outro. Essa atitude, segundo o autor, faz parte do mesmo quadro da indiferença geral pelo sofrimento alheio que governa o país, sejam os cidadãos com deficiência, representados pela figura de tio Gerónimo, ou mais recentemente, as vítimas da narcoviolência, sobre as quais o mais comum é supor que "eles fizeram alguma coisa" para terminarem assim.

Uma crítica semelhante da indiferença generalizada e do distanciamento emocional que governa o país é feita também pelo renomado autor mexicano, Juan Villoro, que alerta:

El narcotráfico ha ganado batallas culturales e informativas en una sociedad que se ha protegido del problema con el recurso de la negación: "los sicarios se matan entre sí". Más que una rutina aceptada o una indiferente banalización del mal, las noticias del hampa han producido un efecto de distanciamiento. Siempre se trata de desconocidos, gente lejana o rara, que sabrá por qué la degüellan. [...] La estrategia defensiva de no mirar o de asumir que los atracos ocurren lejos, en un parque temático del ajuste de cuentas para el que por suerte no tenemos entradas, se ha venido abajo. [...] El crimen ya no puede ser relegado a la región tranquilizadora de lo ajeno (VILLORO, Juan, 2010). 


\section{Conclusão}

É importante ressaltar que, em contraste com a visão solidária com os atingidos que vemos em Contrabando e Un vaquero cruza la frontera en silencio, a maior parte dos romancistas que abordam o tema das drogas no México se mostra fascinada, não com as vítimas, mas com os assassinos e autores da violência. Mesmo um rápido olhar nas dezenas de contracapas das narconovelas publicadas na última década pelos autores mencionados anteriormente, comprovaria que predominam entre eles personagens cheios de adrenalina, os quais impulsionam a trama desses textos: os assassinos profissionais, matadores de aluguel, líderes do tráfico, os pequenos traficantes, as "narcocinderelas", os narcocorridistas, os cybers-traficantes, os meninos e meninas (morros e morras) do tráfico. Essa é uma razão adicional pela qual o romance de Rascón Banda - onde prevalecem as vozes dessas almas perdidas narrando uma tragédia pessoal que se transforma em uma tragédia nacional de proporções épicas - contrasta radicalmente com o mar de publicações que não veem no fenômeno das drogas a raiz de uma tragédia nacional, mas a matéria-prima para um romance de ação.

Escritos com uma diferença de vinte anos, Contrabando e Um vaqueiro cruza a fronteira em silêncio revelam a trágica situação dos povos do norte, tão desprotegidos e devastados pela violência em 1991, quando foi escrito o romance de Rascón Banda, como em 2011, quando o texto de Osorno foi publicado. Sendo ambos os autores provenientes da fronteira norte, eles estão envolvidos com sua terra natal e com o momento histórico que vivem, e foram testemunhas da impotência e do abandono do povo diante da violência desencadeada pelos traficantes aliados àqueles que, teoricamente, deveriam proteger a lei. Eles se sensibilizam com a história que contam, com uma capacidade exemplar de empatia e de se colocar no lugar do outro, elementos chave de sua postura ética que os diferenciam totalmente da maior parte da produção literária sobre o tema, a qual, como 
mencionei, tende a transformar a tragédia nacional em thriller e romance policial, os estilos preferidos da narconarrativa mexicana.

Além dessa postura ética louvável, ambos compartilham do interesse pela busca da melhor maneira de narrar o impacto individual e coletivo do tráfico de drogas, refletido nessa pergunta sobre como escrever sobre o silêncio, que se apresenta nitidamente no texto de Osorno, e fica implícita no romance de Rascón Banda. Suas obras esteticamente inovadoras, intensamente sentidas e de um impacto emocional profundo sobre o leitor, oferecem uma resposta eloquente para essa pergunta. Escritas contra o silêncio e o esquecimento, são a prova irrefutável de que é possível narrar a desenfreada e violenta realidade mexicana sem cair no estilo da imprensa marrom, do folclore ou dos lugares comuns dos romances de ação. São, em resumo, a prova de que é possível dar voz a esta fronteira indescritível onde a barbárie não tem nome (Osorno, 2011, p. 20).

Diana Palaversich é croata, radicada em Sidney, Austrália, onde atua como professora de Literatura e Cultura Latino-Americana do Departamento de Estudos Hispânicos da Universidade de Nova Gales do Sul. É autora do livro "De Macondo a McOndo. Caminhos do pós-modernismo na América Latina" (2005) e inúmeros artigos acadêmicos sobre a literatura mexicana do norte, a narconarrativa e os autores mexicanos nascidos após 1960.

$\sum$ d.palaversich@unsw.edu.au

\section{Referências}

BOSCH, L. Contar la violencia. El País, Madrid, 8 ago. 2009. Babelia.

CACHO, L. Las esclavas del poder. México: Grijalbo-Mondadori, 2010.

DOMÍNGUEZ MICHAEL, C. Escalera al cielo. Una nueva novela lírica. Reforma, [S.I.] 8 ago. 2010.

HERNÁNDEZ, A. Los señores del narco. México: Grijalbo-Mondadori, 2011.

MARTíNEZ, S. La frontera del narco. México: Planeta, 2011.

OSORNO, D. E. Un vaquero cruza la frontera en silencio. La historia de Geró- 
nimo González Garza. México: Conapred, 2011.

OSORNO, D. E. Manifiesto del periodismo infrarrealista. Narco News Bulletin, 12 ago. 2011. Disponível em: <http://www.narconews.com/Issue67/article4489. html>. Acesso em: 12 ago. 2011.

PÉREZ, L. El cartel negro. México: Grijalbo-Mondadori, 2011

RASCÓN BANDA, V. H. Contrabando. México: Planeta, 2008.

VILLORO, Juan. La alfombra roja. El malpensante, n. 105, fev. 2010. Disponível em: http://www.elmalpensante.com/index.php?doc $=$ display_contenido\&id $=825$

Recebido em: 01/09/2013

Aceite final: 05/10/2013 